\section{Draw - Interactions and extensions in the process, project and artistic work. Case study of William Kentridge}

Noemia Herdade Gomes litosmia@gmail.com

Faculdade de arquitectura da Universidade do Porto, Portugal

Gomes, Noemia Herdade; (2012) "Draw - Interactions and extensions in the process, project and artistic work. Case study of William Kentridge", p. 256-260 . In: Barbosa, Helena; Quental, Joana [Eds]. Proceedings of the 2nd International Conference of Art, Illustration and Visual Culture in Infant and Primary Education. São Paulo: Blucher, 2015. ISSN 2318-695X, ISBN: 978-989-98185-0-7 DOI 10.5151/edupro-aivcipe-49

\section{Abstract}

The work of William Kentridge, the internationally renowned south-African artist, constitutes the basis of this thesis dedicated to the study of the interactions and extensions in the process, project and works of art that can be achieved through the Drawing. The research, classification and organization of more than 5.500 documents, collected at the artist's studio, under his supervision, organized into a database developed by this thesis' author, allow for a more global perspective on the creative methodologies of William Kentridge.

The observation of the above mentioned documents, together with a comprehension of their role on the development of Kentridge's art work, allowed to distinguish a series of creative technologies that constitute, per se, an unusual set of mediums and procedures converging into unique creative results. These processes adopt the contribution of the technologies of photography and film which are used together with other processes of drawing representation. This thesis aims at understanding drawing as high potential creative process by offering an analytical view on the creativity processes on the work of William Kentridge and how his work, departs from theatre and Opera to encompass other domains of artistic creation such as architecture and design.

Art, Contemporaneo Art, Drawing, Creative Methodologies, William Kentridge

\section{Introduction}

On the 27th of January 2007 in Johannesburg, South Africa, William Kentridge (WK) set aside "five minutes" of his valuable time to sit down and speak with me. The conversation stretched on for a further 15 minutes, which gave me enough time to introduce myself and explain my intentions of a possible research for my PhD to develop around his work. This brief conversation gave spark to an intense and personal relationship with the artist, with his environment and its context, a relationship, which lasted for approximately four years only ending on the 27th of August 2010 with my return to Portugal. This relationship resulted in the setting up of and development of a database on the work of the artist, 5577 files, built on the applicationFile Maker Pro, evolving from a simple model structure to a network model, covering a wide typology of objects that passes through different media that were recorded, unveiling new material, never before examined and denouncing importance for better understanding of the artist's work. This data was left at the WK's studio and it has continued to be developed and updated, thus becoming a valuable tool for the artist's studio and future research as well essential for this thesis that encompasses a period of 40 years of artistic production of the artist WK, from the 1970s to the year 2010. 
$2^{\text {nd }}$ International Conference Art, Illustration and Visual Culture in Infant and Primary Education $2^{\circ}$ Congreso Internaciona

Arte, Ilustración y Cultura Visual en Educación Infantil y Primaria $\circ$ Congresso Internacional

de Arte, Ilustração e Cultura Visual

na Educação Infantil e Primária

The motivations for our actions stem from our own existence, which we can identify as threefold: moral, environmental and instrumental motivations, justify the make up and divisions of this thesis in the following chapters:

BRIEF CHRONOLOGICAL CONTEXT explores the chronological context of the artist, from his childhood until his consecration as an artist. This chapter is a moral entity that arouses feelings of transforming the artist's inherited reality. The primary motivation is justified by his social and political involvement and by his relentless desire to be an artist, which is what led him to assume a position of anxiety and restlessness. The motivations of a moral nature are confined by matricidade copyright of his work.

REFERENCE SOURCES: EXTENSIONS, CONTAMINATION AND CONNECTIONS: consists of an essay on the referents, references and sources which are predominant in the artistic production of WK, throughout time. This chapter is an inherited entity outside of which, we are ourselves subjects. Consisting of an environmental nature that corresponds to the historical condition of being in the world, of an awareness of context, where the natural landscape, the social, the urban, the cultural, the geographical and the political contexts highlight the link and real connection to the world. In this sense, this environmental motor is everything that involves the artist, who, neither dormant nor passive, is a consequence of this environment

DRAWING - MOVING IMAGE: INTERACTIONS AND NEW GRAPHICAL CONFIGURATIONS deals with the moving image through a relationship between the history of the image over time and the graphic production of the author. This motivation attempts to find in the anatomy of the perception, the means of efficiency for visual communication that justifies all the experimental effort. This system of appropriation of visual knowledge, brings together such diverse themes; such as the use of the cameras, processes, ways and means in which the body of work is motivated not only by mechanics but is technologically criticised. In adopting the cameras and paradigms the technical processes are evolutionising in a hybrid form.

DRAWING - PROCESS, PROJECT AND WORK: INSTRUMENTAL INTERACTIONS, PROCESSES AND PERCEPTIVE ACTIONS is made up of a detailed chronological survey of WK's work from the years 1970 to 2010, describing in detail all the strategies (procedural) and developed (processes created) by WK during his creative process. The identification of these processes was initially made by the readings of the drawings already done in comparison to the procedures, means and techniques. Therefore, we can see and understand the evolution that each process has undertaken over these four decades. I have found that through the decades, the processes developed initially on a limited and isolated scale, have evolved naturally to a hybrid set of mergers, where the three-dimensional stage space is the meeting point for excellence.

CASE STUDY: CARNETS D'EGYPTE 2010, examines in detail the last project observed in the studio of the artist, identifying in detail its constitution with further interpretative analysis. The last section of this chapter ceases to be a descriptive and a comparative approach to gather a significant body of work which is somewhat unique, in order to foster new readings. This sets the tone for the development of the last chapter entitled - Rethinking the drawing.

RETHINKING THE DRAWING, intends to critically compile the creative technologies, which embraces concepts, processes and strategies adopted in the work of WK, throughout his production by bringing new contributions to the idea of drawing as an instrument of creation.

The title of the dissertation is composed of two parts that are in effect integrated into just one. The first - Drawing: interactions and extensions in the process, project and artwork - and the second - the artist's work as a case study. Reversing this order, WK uses the drawing as the starting point in his creative process, which is dealt with in an uncompromising, open and uncertain form. The drawing is used to think, to represent and to view the images in an order that its own process actually establishes for you. It is this network of anachronistic associations that these interactions are established therefore producing extensions of the creative process. And so, it is these interactions that assume reactions or stimuli that are developed transposition techniques for other contexts and technological systems. These extensions in the drawing outweigh and surpass the limited scope of the domain of the scale in just two dimensions to 
$2^{\text {nd }}$ International Conference Art, Illustration and Visual Culture in Infant and Primary Education $2^{\circ}$ Congreso Internacional

Arte, llustración y Cultura Visual en Educación Infantil y Primaria
Congresso Internacional

de Arte, llustração e Cultura Visual

na Educação Infantil e Primária

\section{Creative Technologies}

Figure 1 William Kentridge's photograhy of found in the studio. Database ref 593. Copyright WK; Charcoal drawing for WEIGHING and WANTING 1997, Nine Drawings for Projection, animated film, charcoal drawing under camera, serie of circa 25 drawings, $16 \mathrm{~mm}$, transfer to video 6':20". Database ref.593. Copyright WK instead give it new operative and mental fields. With the introduction of a third dimension: Space - three dimension drawing and a fourth dimension: Time - dynamic drawing can address and bridge the holistic dimension of the total body of work. In the case of WK, studied herein, it represents the single convenience of an articulated methodology, using a set of creative technologies that can identify throughout the artistic staging process: in the process stage, in the project stage and, conclusively, in the phase of communication of the artistic body of work.

These "new technologies" are based on observation as an instrumental, artistic intervention, which is made operational through the cultural, social and historic environment, making clear the intention of discovery and promoting new approaches to alternative knowledge to the language of consciousness. A persistent methodology of reconstructing, which being exposed to chance, reclaims the authority of the sub or even the unconscious, which is retrieved out of the processes of alienation, refusing deductive reasoning, catalysed instead by the unconscious.

The creative process of WK starts with the drawing, which is transported, analysed, evaluated, processed and transformed until the "consistency of the idea," is reached. This will be gradually obtained through as WK tries out the idea on various means, techniques and instruments in an expression of urgency. The construction of meaning is in the constant challenge of finding strategies to make sense .

The opportunities of revelation that arise in the drawing process do not look for a logic sequence, but instead they stop, purposely looking for moments to break its appropriateness. The representation feeds on the photographic argument, the light tells the truth. In opposition to the classical process of deductive linear exertion and endeavour for an expected result in a converging movement, the process of WK is presented inversely: indeed it is the result that finds the author in a fragmented, temporal and occasional movement.

Analytically deconstructing the artistic work to recognise the technological models of production, in the belief that these technological models are also models of reflection in the construction and constitution of a set of Creative technologies. The Creative technologies include methods, procedures and results that from here I shall consider holistically as functional machinery:

\section{Camera}

Function: Recollection of natural or set designed still images Operation: Collect thematically oriented iconographic material Purpose: Record to memory in small fractions of time

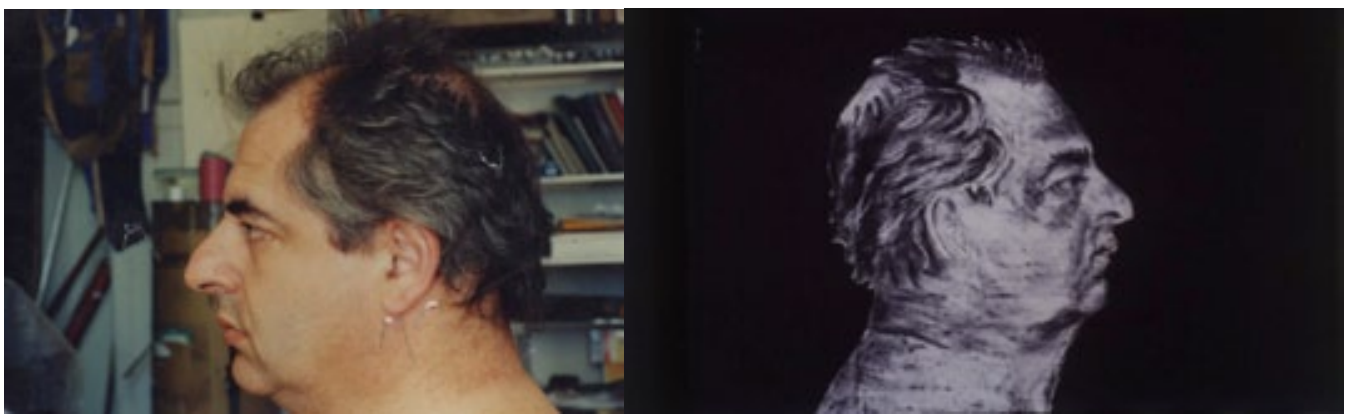

Video camera and tripod

Function: A fixed video camera that documents real moments - blind machine

Operation: Automatic registration of work undertaken

Objective: Being aware of the process from a distance

Truca camera

Function: Cinematic animation camera that captures images of static sets Operation: Production of animated films from a limited number of media

Objective: To construct narratives with a low production cost 
$2^{\circ}$ Congresso Internaciona

de Arte, Ilustracão e Cultura Visual

na Educação Infantil e Primária

Over-projection camera

Function: Over-exposure of an immaterial image projected on the real image Operation: Projection of single or multiple virtual images in simple or complex plans Objectives: Over-exposure leading to a fusion of readings and narratives

Episcope

Function: To redraw the images with variations in size and scale

Operation: De-contextualisation of the image from the outline drawing

Objective: Inter-contextual transfer of graphic images

Silhouette camera or the Plinio camera

Function: To flatten and make black and white the complexity of three-dimensional shape Operation: Overhead light between the object and plan of representation

Objective: Implied by own interpretation

Automatic camera

Function: Creative production of the image from the real image

Operating: Collating various materials or objects to realise the imaginary

Objectives: To test and play with what is around you to generate thought

Predictive camera

Function: To link a diverse set of systems and elements through scale models

Operation: Simulating and pre-visualising the result of the relationship between the differing set of elements (light, shape and space)

Objective: To anticipate, study, implement, support and visualize

Imaginative camera

Function: To set up from the action of breaking up the image

Operation: Setting up from memory, be it pre-determined or inclusive of the deconstructed image

Objectives: Reconfigure by similarity and combining fragments of the abstract figures

Revelation camera

Function: To transfer a two-dimensional image to a three-dimensional representation and so transforming the dis-order into order

Operation: Assigning an orbital or cyclical movement so constructing a three dimensional image Objectives: To produce the feeling of exposure and revelation between the terrible and the fantastic

Reticular pantograph machine/camera

Function: Fragmentation of everything

Operation: Dividing the image by regular orthogonal lattice

Objective: To de-contextualise the fragment for the overall discontinuity so re-entering a whole new discontinuous image

Marey's photographic gun camera

Function: The production of static images of images taken sequentially

Operation: Progression of the image over time

Objectives: To fix and freeze time

Hallazgo camera

Function: To unveil and uncover

Operation: The deconstruction and inversion of celestial mechanics

Objective: To rediscover the revealed 
2nd International Conference Art, Illustration and Visual Culture in Infant and Primary Education
Congresso Internacional

de Arte, llustração e Cultura Visual

na Educação Infantil e Primária

\section{Conclusion}

The drawing procedure is seen as unfolding throughout the work - it is not the only way, nor the end of the drawing. In view of a visual model, the drawing passes through different medias that are indispensable for the creation of ideas, so forth creating a multiple polysemic of images that simultaneously constitute and overall infer different points of view. As important as the thinking of WK is the result of the more committed process in knowing when to stop rather than when to finish. WK does not run the temptation of overcoming the inherent limits represented, insisting on voluntarily interrupting the process, therefore avoiding the quaint, scenic and picturesque image. So when the drawing process changes, the discomfort of the unknown has already been comforted by this stop. This stop introduces the effect of suspension that will ultimately provide an important representation of oneness with the work. When drawing, WK establishes a membrane between the reality of what he sees and what he thinks on the sheet of paper. The separation between who does the drawing and what the person sees, is an interval, a space "imagery" where thought can occur through the entire subversion of linearity, fragmentation, random reordering or hierarchical inversion. These are all constructions of suggestion.The failure to give the viewer and observer a certain image, means they (the viewer) are given generosity in that how they are to "complete" the image stays almost in suspense. The drawing not only meets the representation of an abstract cognitive process, but also rather, is itself a cognition agent and creativity distances them from pre-determined thought by linearly planned steps leading to the final product. The preparation involves thinking and planning, only later revealing the known.The significance of the image can only arise after the 'dialogue' and can not be pre-established. The appropriation in WK always appears associated with the interaction of the inventory of images, a process of re-writing, re-invention and revisiting. The reconstruction and rebuilding from what exists is a random personalised reality that is broken up by time and space.

Recognising also the drawing as a metaphor of existence itself. In so far as, it does not occur in a coherent system, but multiple fragments that result from a variety of simultaneous thoughts; assigning more importance to the process than results, strategies and tactics of deconstruction: erasure, game and doubt. Photography, Sculpture, Film animation and projection are generated as extensions of the drawing and create access to new images in combination with the conventional art technologies. WK in his creative process sees and visualises the various strategies that can be identified as Creative technologies; the means to prevent the constructed image is a reproduction of a latent or potential image. What in the body of work of WK could be considered as singular, unique and noteworthy, is not so much how each of the Creative technologies were adopted by WK, but rather, how the merger is orchestrated in the search of a conscious multiplicity of forms. Ideas, that broadly interact as a finished drawing is born of many drawings from a playful sense of transcendence. 